\title{
Explicit simulations of stream networks to guide hydrological modelling in ungauged basins
}

\author{
S. Stoll ${ }^{1,2}$ and M. Weiler ${ }^{1}$ \\ ${ }^{1}$ Institute of Hydrology, University of Freiburg, 79098 Freiburg, Germany \\ ${ }^{2}$ Institute of Environmental Engineering, ETH Zurich, 8093 Zurich, Switzerland \\ Received: 5 January 2010 - Published in Hydrol. Earth Syst. Sci. Discuss.: 29 January 2010 \\ Revised: 12 July 2010 - Accepted: 20 July 2010 - Published: 4 August 2010
}

\begin{abstract}
Rainfall-runoff modelling in ungauged basins is still one of the greatest challenges in hydrological research. The lack of discharge data necessitates the establishment of new innovative approaches to guide hydrological modelling in ungauged basins. Besides the transfer of calibrated parameters from similar gauged catchments, the application of distributed data as a hydrological response in addition to discharge seems to be promising. A new approach to guide hydrological modelling based on explicit simulation of the spatial stream network was tested in four different catchments in Germany. In a first step we used a simplified version of the process-based model Hill-Vi together with regional climate normals to simulate stream networks. The calculation of gravity driven lateral subsurface and groundwater flow is used to identify patterns of stream cells, which were compared to reference stream networks and their degree of spatial agreement was evaluated. Significant differences between good and poor simulations could be distinguished and the corresponding parameter sets relate well with the hydrogeological properties of the catchments. The optimized parameters were subsequently used to simulate daily discharge using an observed time series of precipitation and air temperature. The performance was evaluated against observed discharge and water balance. This approach shows some promising results but also some limitations. Although the model's parsimonious model structure could be further improved regarding discharge recession and evapotranspiration, the performance was similar to regionalisation methods. Stream network modelling, which has minimal data requirements, seems to be a reasonable alternative for model development and parameter evaluation in ungauged basins.
\end{abstract}

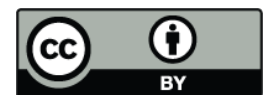

Correspondence to: S. Stoll (stoll@ifu.baug.ethz.ch)

\section{Introduction}

Modelling in ungauged basins is still one of the most challenging tasks for hydrologists. Especially the lack of runoff data, normally used to calibrate parameters of catchment models limits the prospects of success (Sivapalan et al., 2003). To handle this problem, alternative approaches to the conventional fitting of hydrographs have to be established.

The most common approach of transferring parameters from gauged to ungauged basins is based on the assumption that two similar catchments will respond identically to the same input. In the past different specifications of similarity have been presented. Blöschl (2005) describing this traditional concept highlighted that the catchments located close to each other are expected to respond similarly, while it is assumed that the regulation mechanisms (e.g. geology) are constant. Another method to identify similar basins is the comparison of catchment attributes, e.g. soil types. The hydrological response is assumed to be similar, if the feature is identical. Numerous regionalisation methods were applied to establish relationships between model parameters and attributes to transfer them to ungauged basins (e.g. Nathan and McMahon, 1990; Abdulla and Lettenmaier, 1997; Kokkonen et al., 2003; Parajka et al., 2005). Other approaches try to define similarity by the comparison of calculated indices. Their objective is to achieve few values which are representative of the whole catchment. It is assumed that the calculated indices integrate all relevant features. An example is the instantaneous geomorphologic hydrograph introduced by Rodriguez-Iturbe and Valdes (1979), which relates runoff with geomorphologic characteristics.

Several studies (e.g. Merz and Blöschl, 2004; Seibert, 1999) tested the performance of regionalised model parameters. Even though they reported acceptable model efficiencies, they detected poor correlation between catchment attributes and model parameters and a significant decline of model performance when moving from gauged to ungauged

Published by Copernicus Publications on behalf of the European Geosciences Union. 
basins. Blöschl (2005) explained this drop in performance with the possibility that the usually regionalised catchment features, e.g. land use, may not be relevant for the major hydrological processes, which take place in the subsurface and control the response. Furthermore, he emphasised the problem of uncertainty of the calibrated parameters. Exporting parameters from gauged to ungauged basins does not guarantee similar good results as under the circumstances they were determined. This is caused by the missing balancing effect of the calibration process on specific catchment heterogeneities and the compensation on input, output and structural uncertainties.

An alternative to regionalisation is the use of spatial hydrologic patterns. Besides runoff data, alternative hydrological responses can be used to calibrate model parameters. For example, observed spatial patterns like snow cover and runoff occurrence are suitable for calibrating and evaluating distributed hydrological models (Refsgaard, 2001; Grayson et al., 2002). Bauer et al. (2006) used a coupled physically based surface water/groundwater model to study the impacts of human interventions and climate change on the size of the wetlands of the Okavango Delta. Due to sparse and unreliable runoff data, they compared binary satellite-derived inundation patterns with modelled flooding extents to calibrate seven model parameters. The evaluation on groundwater levels showed satisfying results and the characteristics of the annual floods in the delta could be reproduced successfully. Blöschl et al. (2002) presented an approach to calibrate model parameters in the highly karstified Schneealpe catchment in the Austrian Alps using satellite-derived patterns of snow cover for parameter identification of a snow melt module. This improved the model significantly compared to a standard calibration on runoff data. Similar results are presented in a recent paper by Jost et al. (2009). Generally speaking, spatial patterns of different hydrological variables are suitable, respectively recommendable, to calibrate distributed hydrological models (Grayson and Blöschl, 2000; Blöschl, 2005). Besides this, spatial hydrological data also provides the opportunity to evaluate the whole model conceptualization and the implemented processes. If, for example, a model does not reflect the observed snow patterns although the discharge was modelled accurately, a revision of the conceptualisation should be carried out nonetheless. Spatial data can deliver additional decision support when choosing between different parameter sets to minimize the equifinality problem (Beven, 1993). However, it is crucial, that the used spatial data is representative of the processes and parameters which should be evaluated. Another condition for the application in ungauged basins arises from the fact, that data especially spatial data are per definition very rare except they are monitored for another purpose. A comprehensive overview of modelling strategies in ungauged basins can be found in Blöschl (2005).
A different approach can be taken by combining hydrology and geomorphology, following Rodriguez-Iturbe and Rinaldo (1997) reporting that a “(...) drainage network itself may be viewed as a reflection of the runoff-producing mechanisms occurring in a basin". Different approaches to examine the evolution, initiation, and description of drainage networks have been applied in the past. The most famous review on stream networks by Horton (1945), in which precipitation rate, relief and infiltration capacity and thus overland flow were indentified as the dominant features. Dunne (1969) presented that additional processes like groundwater inflow into the stream influence the initiation of stream networks (see also Lobkovsky et al., 2007). Groundwater inflow (springs or diffusive) is identified as a key process in drainage network development in humid areas. Several authors (De Vries, 1994, 1995; Troch et al., 1995) emphases that in humid areas the stream channels can be classified as outcrops of the groundwater flow system. The channels represent the interface between groundwater flow and associated surface drainage system. The evolution of the channel network is dominated by subsurface permeability, climate and large scale topography. According to the presented theory and equivalent to the variable source area concept of Hewlett and Hibbert (1967), De Vries (1995) described the initiation of stream network as a self-organising process controlled by seasonal meteorological variations resulting in groundwater level fluctuations. Those fluctuations generate an expanding and contracting stream network with a changing number of participating draining streams.

According to the presented theories and assuming that the underground properties like transmissivity are representative for the initiation of the drainage network, we propose to evaluate a hydrological model for ungauged basins using spatial explicit simulations of the stream network. Stream networks predicted by a hydrological model and driven by climatic data can be compared with mapped stream networks derived from maps or remote sensing data, which are generally available even in ungauged basins. Through the comparison on the basis of a suitable objective function it should then be possible to indentify a reasonable set of model parameters. This approach also provides the opportunity to reduce the temporal dependence of parameter identification, by using long-term climatic data instead of a few years of observed meteorological data. In this paper we want to test this hypothesis by setting up a parsimonious model for four catchments in the federal state of Baden-Württemberg, Germany. The parameters in best agreement with the stream network map are subsequently applied to an observed rainfall-runoff time series, where the resulting discharge simulations can be compared with observations. Although, the focus is on exploring the parameter space for subsurface processes the intention of the study is not to establish a new stand-alone calibration approach. Rather, the approach should "guide hydrological modelling in ungauged basins" to receive additional knowledge about the catchment, in particular the subsurface, 
and the model. The approach shows the potential of processbased modelling of stream networks for the ungauged basin problem.

\section{Methods}

\subsection{Model approach}

We chose the process-based, distributed model Hill-Vi (Weiler and McDonnell, 2004), which is capable of calculate subsurface flow entering to the surface for every time step, to simulate the stream network. To reduce the number of calibration parameters we simplified the model in such a way that only the main processes affecting the initiation of stream networks are included. Consequently, we simplified the water transport through the unsaturated zone by directly adding rainfall or snow melt to the saturated zone. Only a brief description of the basic concepts and the modifications made are given here. Detailed information about the original model structure can be found in Weiler and McDonnell $(2004,2005)$.

The spatial explicit model is based on a storage representing the complete subsurface zone for each grid cell. To represent both the compaction of the soil with depth and the transfer to the less permeable bedrock, an exponential depth function for the specific yield is implemented:

$S(z)=\int_{z}^{Z} n_{0} \exp \left(-\frac{z}{b}\right) d z$

where $S$ is the storativity (m), $n_{0}$ the specific yield at the soil surface, $b$ the decay coefficient, $z$ is the depth into the soil profile (positive downward) and $Z$ is the total depth. Equivalent to the specific yield an exponential decline of the hydraulic conductivity is also realized

$T(z)=\int_{z}^{Z} k_{0} \exp \left(-\frac{z}{b}\right) d z$

where $T\left(\mathrm{~m}^{2} / \mathrm{s}\right)$ is the transmissivity and $k_{0}$ is the saturated hydraulic conductivity at the soil surface $(\mathrm{m} / \mathrm{s})$. We assumed that the decline is caused by the same effects also reducing the specific yield so that no distinction must be made in the determination of the decline coefficients (Selker et al., 1999)

The water balance of the saturated zone is calculated by the input of precipitation and snowmelt, the lateral in- and outflow as well as the actual evapotranspiration. When the water table rises above the ground level, all water excess is defined as overland flow and the corresponding cell is defined as a stream cell. Within the saturated zone the DupuitForchheimer assumption (Freeze and Cherry, 1979)

$q(t)=T(t) \beta w$
Table 1. Calibration parameter.

\begin{tabular}{lll}
\hline Parameter & Explanation & Unit \\
\hline$Z$ & total depth of the subsurface & {$[\mathrm{m}]$} \\
$b$ & decay coefficient & {$[-]$} \\
$n_{0}$ & specific yield at the soil surface & {$[-]$} \\
$k_{0}$ & saturated hydraulic conductivity & {$[\mathrm{m} / \mathrm{h}]$} \\
& at the soil surface & \\
\hline
\end{tabular}

where $\beta$ the water table slope and $w$ the width of the flow (m) is used to calculate lateral subsurface flow. Based on this concept, Hill-Vi calculates the downslope routing of the subsurface flow by a grid cell by grid cell approach, which was introduced by Wigmosta and Lettenmaier (1999).

As the consequence of the parsimonious model structure neglecting an explicit unsaturated zone the actual evapotranspiration $\mathrm{ET}_{\mathrm{A}}$ is calculated by a linear function of the groundwater table depth:

$\mathrm{ET}_{\mathrm{A}}(t)=\left\{\begin{array}{l}\mathrm{ET}_{\mathrm{P}}(t) \quad \text { if }(Z-H(t)) \leq 0.5 \\ \operatorname{ET}_{\mathrm{P}}(t)\left(\frac{H(t)+0.5}{Z}\right) \text { if }(Z-H(t))>0.5\end{array}\right.$

with $H$ is the water table depth at time step $t$. Due to the lack of climatic humidity data, the approach of Thornthwaite (1948) is used to estimate potential evapotranspiration $\mathrm{ET}_{\mathrm{P}}$. Additionally, a simple degree-day-approach snow melt routine based on the concept realised in the HBV model (Bergström, 1995) was implemented into Hill-Vi. The parameters of the snow melt module are estimated a priori based on simulations with similar degree day models in the region (Uhlenbrook, 1999) and were not subject of calibration. As a result of the modifications, the number of the calibration parameters, which are listed in Table 1, was reduced to four.

\subsection{Stream network simulations with climate data}

In order to consider the influence of the climate on stream network development mean monthly temperature and precipitation data of the climatic reference period 1961-1990 are used as model input. The mean values were apportioned to the number of days of the month afterwards smoothed by a 30-day running average. After a one-year warm up period the stream networks were simulated in daily time steps based on a 50 by $50 \mathrm{~m}$ digital elevation model (DEM).

To optimize the four parameters, an objective function comparing the modelled spatial distribution of stream cells and a gridded stream network map is required. The stream network was derived from a digital version of streams exceeding a length of $500 \mathrm{~m}$ in the topographic map of BadenWürttemberg (1:200000) and was rasterized to a binary raster map with an equivalent resolution to the binary model 
Table 2. Error matrix used for Kappa statistics.

\begin{tabular}{ccccc}
\hline \multirow{4}{*}{ Model } & \multicolumn{4}{c}{ Reference } \\
\cline { 2 - 5 } & \multicolumn{1}{c}{1} & $k$ & $p_{i}$ \\
\cline { 2 - 5 } & 1 & $p_{11}$ & $p_{1 k}$ & $p_{1}$ \\
\cline { 2 - 5 } & $p_{k 1}$ & $p_{k} k$ & $p_{k}$ \\
\hline & $p_{j}$ & $p_{1}$ & $p_{k}$ & 1 \\
\hline
\end{tabular}

output differing in stream cells and no-stream cells for each time step.

As objective function we choose the Kappa goodness-offit statistics, which was introduced by Cohen (1960) to compare independent psychiatric diagnoses. This turned out to be the most sensitive criteria, compared to other cell-by-cell approaches which either lack penalties for false positive errors or consideration of chance agreements. The Kappa value $K$ is the measure of actual agreement compared to a chance agreement, which are both derived from an error matrix. This discrete multivariate technique has been widely used in different disciplines, e.g. in the field of remote sensing to measure the agreement of two maps (e.g. Monserud and Leemans, 1992; Congalton and Green, 1999). Assuming two maps with two categories (water and no-water), there are agreements of omission (no-water in both maps) and agreements of commission (water in both maps), adding up to the proportion of agreement $p_{\mathrm{a}}$ :

$p_{\mathrm{a}}=\sum_{i=1}^{k} p_{i} i$

Additionally, a chance agreement $p_{\mathrm{c}}$ indicated by the product of the row and column totals is determined from the error matrix (Table 2):

$p_{\mathrm{c}}=\sum_{i=1}^{k} p_{i} \cdot p \cdot j$

Given the premise of a multinomial sampling model, the maximum likelihood estimate of Kappa can be calculated by:

$K=\frac{p_{\mathrm{a}}-p_{\mathrm{c}}}{1-p_{\mathrm{c}}}$

Positive values indicate a meaningful classification with an agreement significantly better than a random one. When the two maps are identical, Kappa takes the value of $K=1$ (Congalton and Green, 1999). Besides the simple calculation, Kappa statistics have the advantage of a standardised result that makes a simple comparison possible.

As mentioned above, the initiation of stream networks is controlled by seasonal variations, which makes it necessary to select a specific season for the comparison with the observed stream networks. Since only perennial streams that

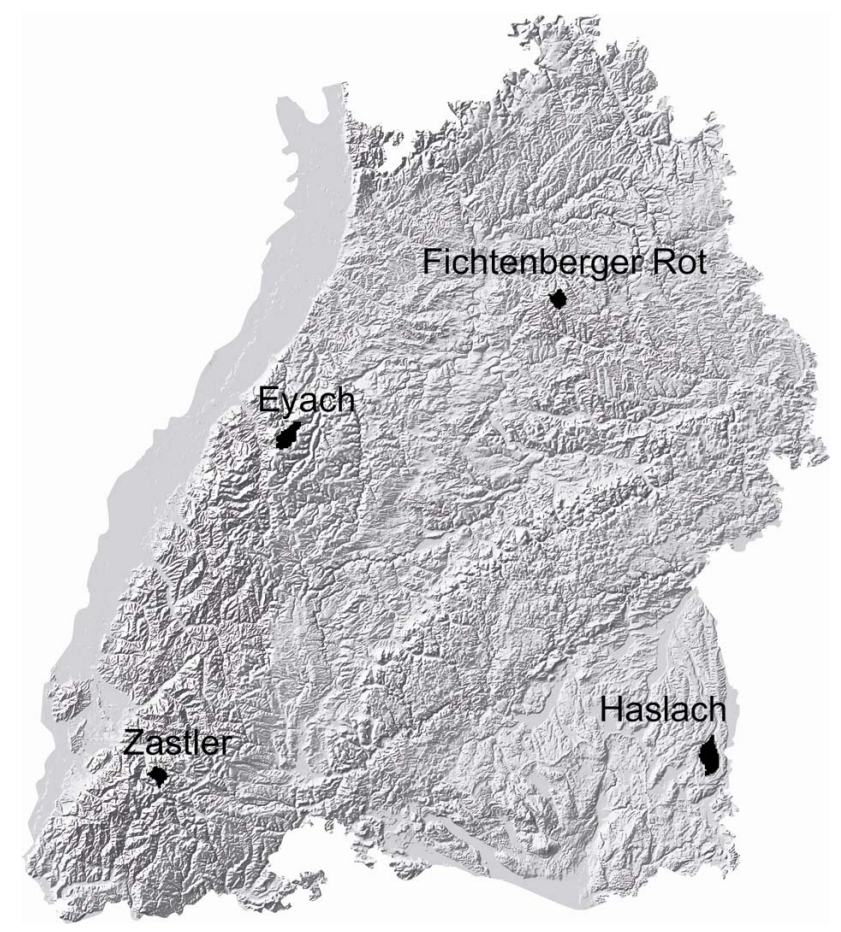

Fig. 1. Orographic map of Baden-Württemberg with the location of the four study sites.

flow also in the summer are mapped, the arithmetic mean of the daily Kappa values, which were calculated for the low flow period in July, August and September, was chosen to evaluate the efficiency of the parameter set. The performances of 3000 randomly chosen parameter combinations in prescribed reasonable boundaries were tested. Within these boundaries the values were uniformly distributed. Furthermore we assumed that the parameters within one catchment were spatially uniform, since the catchments were chosen to be dominated only by one geological bedrock material.

The parameter set which achieved the highest agreement with the reference map was then driven with conventional daily meteorological data. After a warm-up period of one year to initiate the model states, the simulated daily discharge and water balances of two additional years were evaluated with observations at stream gauging sites. Due to the differences in data availability, different years had to be chosen for each catchment.

\subsection{Study areas}

Given the available discharge, precipitation, and air temperature data, we selected four watersheds in BadenWuerttemberg (Fig. 1), which were chosen to gain a maximum variability of essential hydro-geological characteristics to test the approach under various conditions.

The Zastlerbach basin is located within the basement of the southern Black Forest Mountains with elevation ranging 
Table 3. Watershed characteristics.

\begin{tabular}{|c|c|c|c|c|}
\hline & Zastlerbach & Fichtenberger Rot & Haslach & Eyach \\
\hline area $\left(\mathrm{km}^{2}\right)$ & 17.9 & 17.3 & 40.3 & 29.8 \\
\hline $\begin{array}{l}\text { mean elevation } \\
\text { (m a.s.1.) }\end{array}$ & 1053 & 492 & 688 & 790 \\
\hline mean slope $(\%)$ & 35.2 & 8.3 & 5.4 & 22.0 \\
\hline $\begin{array}{l}\text { mean annual } \\
\text { precipitation }(\mathrm{mm})\end{array}$ & 1814 & 1188 & 1024 & 1385 \\
\hline $\begin{array}{l}\text { mean annual air } \\
\text { temperature }\left({ }^{\circ} \mathrm{C}\right)\end{array}$ & 5.6 & 7.7 & 7.8 & 7.2 \\
\hline $\begin{array}{l}\text { mean specific } \\
\text { discharge }(\mathrm{mm} / \mathrm{a})\end{array}$ & 1153 & 529 & 562 & 898 \\
\hline dominat geology & $\begin{array}{l}\text { metamorphic } \\
\text { rock }\end{array}$ & sandstone + marl & $\begin{array}{l}\text { quarternary } \\
\text { material }\end{array}$ & sandstone \\
\hline $\begin{array}{l}\text { Estimated hydr. } \\
\text { conductivity }(\mathrm{m} / \mathrm{s})\end{array}$ & $10^{-6}$ to $10^{-7}$ & $10^{-5}$ & $10^{-3}$ to $10^{-7}$ & $10^{-5}$ \\
\hline dominant soil type & cambisol & podzolic cambisol & luvisol & podzol \\
\hline land use + ratio & $\begin{array}{l}\text { forest }(90 \%) \\
\text { grassland }(10 \%)\end{array}$ & $\begin{array}{l}\text { forest }(44 \%) \\
\text { grassland }(33 \%) \\
\text { agriculture }(15 \%) \\
\text { settlements }(8 \%)\end{array}$ & $\begin{array}{l}\text { grassland }(54 \%) \\
\text { forest }(44 \%) \\
\text { settlements }(2 \%)\end{array}$ & forest $(100 \%)$ \\
\hline
\end{tabular}

from 548 to $1493 \mathrm{~m}$ a.s.l. (above sea level). The underlying bedrock consists of metamorphic rock, covered by shallow periglacial material. Precipitation and temperature is dominated by orographic effects and the Zastlerbach shows a nivoplivial runoff regime.

The basin of the Fichtenberger Rot is situated in the Frankish-Swabian Forest, north-east of Stuttgart. It covers an area of $17.3 \mathrm{~km}^{2}$ and is influenced by cyclonic west wind situations, resulting in a pluvial runoff regime. Above the sandstones and marls of the upper Keuper, the podzolic cambisols and heterogenous land use can be found (Table 3).

The Haslach basin is located near Memmingen in the East of Baden-Württemberg in the region of the upper Swabia. The flat basin has an area of $40.3 \mathrm{~km}^{2}$ and has a pluvial regime. The region of upper Swabia was strongly influenced by several ice ages depositing highly permeable debris and till.

The Eyach basin is located in the northern Black Forest about $35 \mathrm{~km}$ south of Karlsruhe. Sandstones of the lower and middle Buntsandstein are the dominating geology. The basin is covered by coniferous forest growing on podzols and podzolic cambisols. Due to the intermediate altitude the runoff regime shows both an impact of precipitation and snowmelt.

\section{Results}

\subsection{Parameter identification}

The parameter combinations that achieved the best agreements according to the Kappa statistics are listed in Table 4. Additionally, the transmissivity and the storativity over the maximum depth $Z$, both dependent on the decay coefficient, are presented to enable a better comparison among the individual catchments. Generally the Kappa values are quite low with values between 0.15 and 0.22 . The highest Kappa values are reached in the Zastlerbach catchment, followed by the Eyach whereas in the Haslach and Fichtenberger Rot catchment significantly lower values were calculated. The Zastlerbach is also identified as the catchment with the lowest transmissivity and storativity while in the Eyach catchment the highest values can be found. The sensitivities of the parameters are shown in Fig. 2 as dotty plots of transmissivity and storativity. Each black point represents one model run with the calculated transmissivity or storativity against the Kappa statistic. The transmissivity values in the Zastlerbach and the Eyach catchments seem to be well defined with a clear optimum at the lower end of the preset boundary. The Fichtenberger Rot and the Haslach catchments show generally the same tendency with an improvement of model performance with increasing transmissivity, followed by a slight 


\section{Zastlerbach}

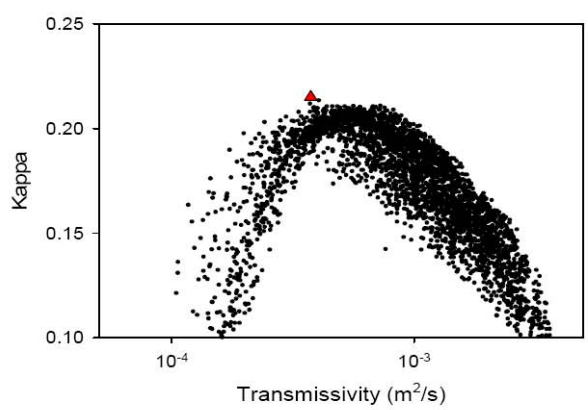

Fichtenberger Rot

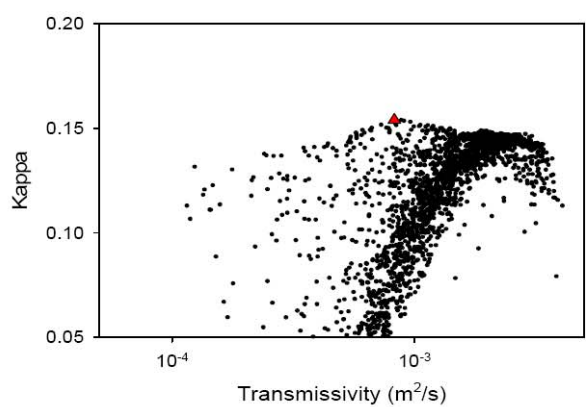

Haslach

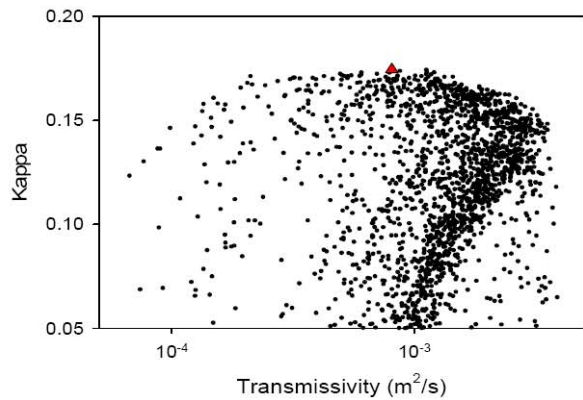

Eyach

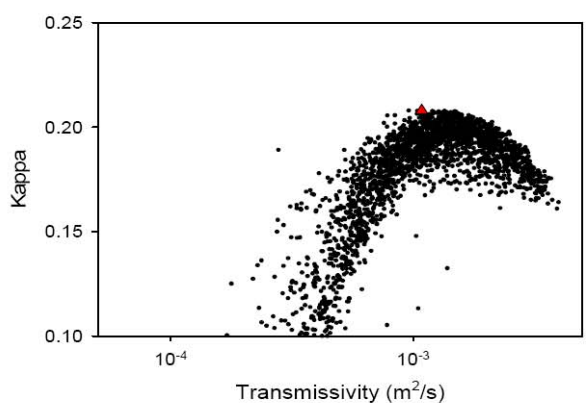

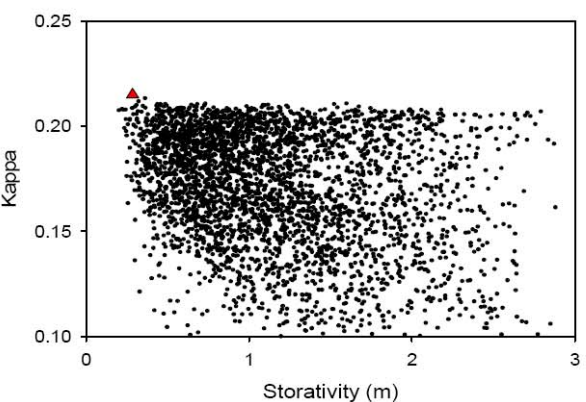
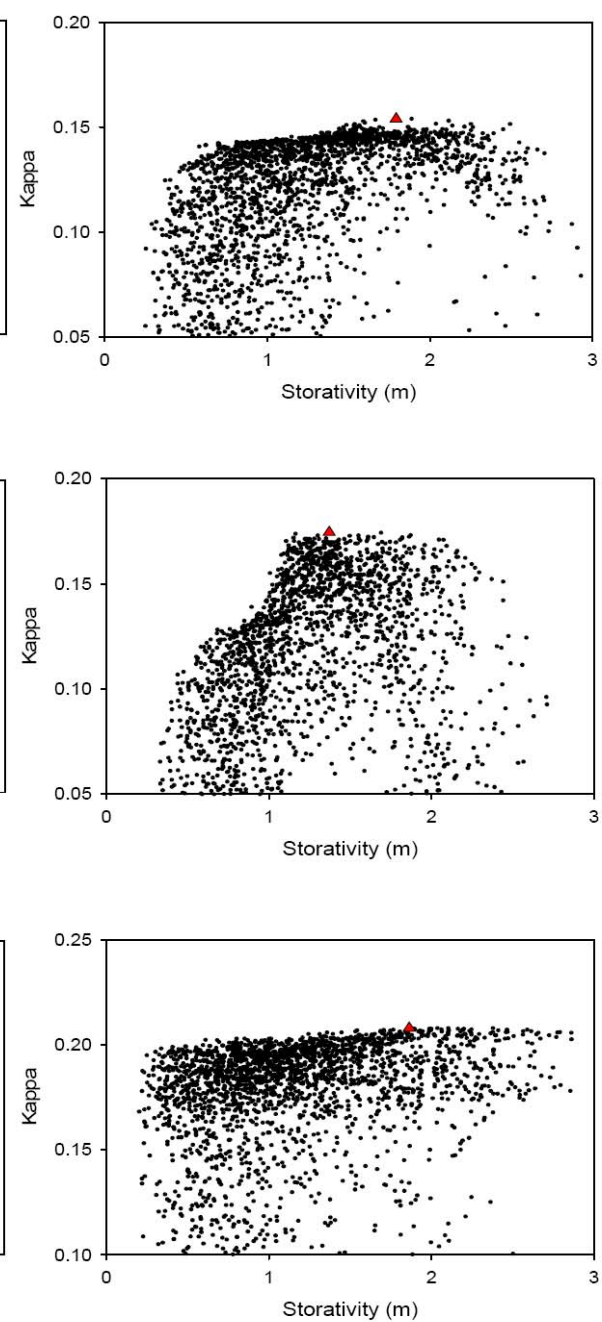

Fig. 2. Dotty plots of transmissivity and storativity.

decline however, the behaviour is not as distinct. Contrary to transmissivity the model perfomance is not very sensitive to variations of the two parameters affecting the storativity. Only for the Haslach and the Fichtenberger Rot a distinct pattern can be identified. The other two show a better performance near the lower boundary, however the optimum have not to follow this general tendency.
The introduced theories indicated that the initiation and spatial extent of stream networks is controlled by subsurface properties and climate conditions. Although there is no quantitative information, the sensitivity of the stream networks on variations of subsurface parameter can be used to evaluate the consistency of the presented theories. Figure 3 shows the reference network (Fig. 3a), the network produced by 

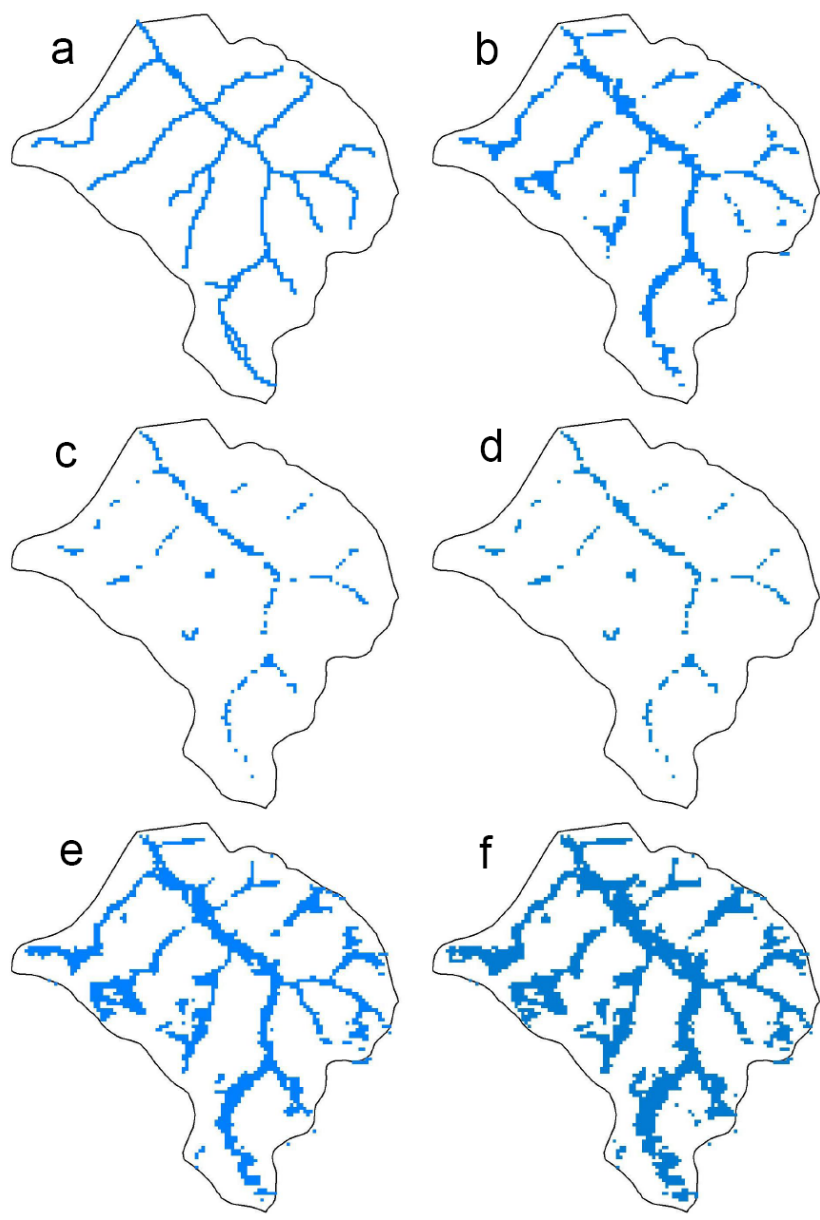

Fig. 3. Zastlerbach reference network (a) and effects of different parameter sets on the spatial distribution of stream cells (b-f).

the best fit parameter set (Fig. 3b) as well as four additional combinations of high respectively low transmissivities and storativities which are listed in Table 5. To assure significant differences, but still reasonable performances, we considered parameter combinations that reached Kappa values between 0.15 and 0.17 . All modelled networks represent the Zastlerbach catchment and are given for the low flow period in late summer. Not surprisingly, the network produced with the best parameter set shows the highest agreement with the reference network. However, compared to the well defined reference stream network it shows several wet patches as well as a general overestimation of the stream width. The same applies for the networks produced with low transmissivities. However, the overestimation of the stream extent is even larger. In contrast to that, simulations with higher transmissivities lack several features compared with the reference. Generally it seems that variations of transmissivity are more sensitive than variations of the storativity, supporting the results of the dotty plot analysis (Fig. 2).
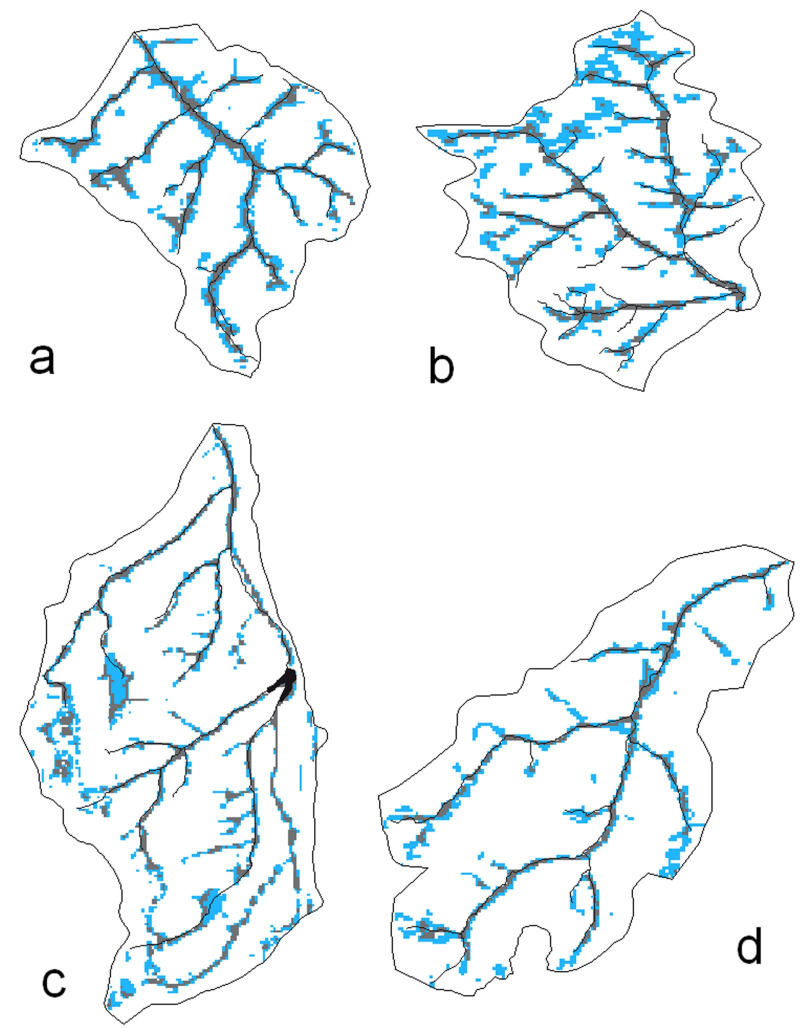

Fig. 4. Seasonal development of the spatial extent of the stream networks of Zastlerbach (a), Fichtenberger Rot (b), Haslach (c) and Eyach (d) with the reference (black line) and the simulated stream networks during spring (blue) and the late summer (dark grey).

Additional to that, the climate conditions have an influence on the temporal distribution of the stream extent. The Groundwater levels are controlled by seasonal meteorological variations, resulting in an expanding and contracting of the stream network. The spatial extent of the stream networks, modelled with the best parameter combinations are given in Fig. 4. Every catchment shows distinctive differences between the extents during the periods with high discharge and those during the low flow period in the late summer. The number of draining streams increases significantly during spring particularly in the headwaters of the catchments.

\subsection{Evaluation}

For the evaluation of the model with the best performing parameter set, different results can be compared with the corresponding observations. A common approach for model evaluation is the comparison of modelled and observed streamflow. The model efficiency after Nash and Sutcliffe (1970) $n_{\text {eff }}$ is calculated to quantify the agreement. Additionally, the transformed $\operatorname{logarithmic}$ efficiency $\log n_{\text {eff }}$ is computed to 
Table 4. Best parameter sets and maximum Kappa value for the optimization of the four catchments.

\begin{tabular}{lcccc}
\hline Parameter & Zastlerbach & $\begin{array}{c}\text { Fichtenberger } \\
\text { Rot }\end{array}$ & Haslach & Eyach \\
\hline$Z(\mathrm{~m})$ & 2.20 & 15.87 & 16.60 & 23.47 \\
$b$ & 2.30 & 3.30 & 4.33 & 4.98 \\
$n_{0}$ & 0.20 & 0.55 & 0.32 & 0.38 \\
$k_{0}(\mathrm{~m} / \mathrm{h})$ & 0.95 & 0.91 & 0.69 & 0.79 \\
\hline$T\left(\mathrm{~m}^{2} / \mathrm{s}\right)$ & $3.8 \mathrm{E}-04$ & $8.3 \mathrm{E}-04$ & $8.1 \mathrm{E}-04$ & $1.1 \mathrm{E}-03$ \\
$S(\mathrm{~m})$ & 0.29 & 1.79 & 1.37 & 1.86 \\
$K$ & 0.22 & 0.15 & 0.18 & 0.21 \\
\hline
\end{tabular}

Table 5. Best parameter set and variations of high respectively low transmissivities and storativities in the Zastlerbach catchment and the resulting Kappa values and streamflow model performance.

\begin{tabular}{lcccrr}
\hline Parameter set & $T\left(\mathrm{~m}^{2} / \mathrm{s}\right)$ & $S(\mathrm{~m})$ & $K$ & $n_{\mathrm{eff}}$ & $\log n_{\mathrm{eff}}$ \\
\hline$b$ (best fit) & $3.8 \mathrm{E}-04$ & 0.29 & 0.22 & 0.39 & 0.48 \\
$c$ & $2.4 \mathrm{E}-03$ & 0.62 & 0.15 & 0.15 & 0.02 \\
$d$ & $2.7 \mathrm{E}-03$ & 1.89 & 0.15 & 0.12 & -0.21 \\
$e$ & $1.2 \mathrm{E}-04$ & 0.26 & 0.16 & -0.37 & -0.31 \\
$f$ & $1.4 \mathrm{E}-04$ & 2.20 & 0.16 & -0.37 & -2.79 \\
\hline
\end{tabular}

focus on the performance of the low flow periods (Table 6). The hydrograph for the Zastlerbach during 2004 and 2005 is illustrated in Fig. 5. It shows a good agreement and the streamflow dynamics are predicted correctly. Especially the peaks are represented well. The low flows are slightly overestimated, which is also visible in the flow duration curve of the same period shown in Fig. 6. Larger differences occur mainly during recession periods and in the spring. The predictions for the Fichtenberger Rot show better results for the low flow periods whereas the peak flows are underestimated. However, the optimized parameter set and model is not able to predict the recession process satisfactorily. Although the second highest efficiency is reached in the Haslach catchment, a distinct underestimation of the low flows can be observed, which is clearly obvious in the flow duration curve and a very low value of the logarithmic efficiency. The highest model efficiency with a value of 0.6 is reached in the Eyach catchment. This seems surprising because the visual impression of the hydrograph as well as the flow duration curve do not look very convincing. The discharge is overestimated continuously except for the peaks.

To evaluate the sensitivity of the parameters the predicted discharge of the Zastlerbach generated with the test parameters listed in Table 5 are presented in Fig. 6. Parameter set $c$ shows only damped reaction on precipitation and snow melt
Table 6. Model performance for model evaluation using daily climate and streamflow data.

\begin{tabular}{lcccc}
\hline & Zastlerbach & Fichtenberger Rot & Haslach & Eyach \\
\hline period & $2004-2006$ & $1991-1993$ & $1966-1968$ & $1991-1993$ \\
$n_{\text {eff }}$ & 0.39 & 0.49 & 0.56 & 0.60 \\
Log $n_{\text {eff }}$ & 0.48 & 0.56 & 0.07 & 0.34 \\
\hline
\end{tabular}

events. This behaviour is even worse for the parameter set $d$, which shows nearly a constant baseflow. Contrary to that the parameter sets $e$ and $f$ are reacting very fast. However, they underestimate baseflow. The model efficiencies (Table 5) of all test parameter sets are significantly lower compared to the best fit parameter set.

Besides the comparison of the hydrograph dynamics, the calculation of water budgets can provide additional, more integrative information about the performance of the model simulations. The simulated average precipitation $(P)$, evapotranspiration ( $\left.\mathrm{AET}_{\mathrm{mod}}\right)$, change in storage $(\Delta S)$ and discharge $\left(Q_{\text {mod }}\right)$ for the simulated period are compared with the discharge measurements $\left(Q_{\text {obs }}\right)$ (Table 7). A considerable overestimation of the yearly runoff can be observed except for the Haslach catchment, which is consistent with the analysis of the flow duration curves. In the Haslach catchment, overestimated peak discharges compensate the underestimation of low flows resulting in a very good fit of the annual runoff. The permanent overestimation in the Eyach leads to a distinctive runoff surplus of nearly $200 \mathrm{~mm}$ per year whereas in the other two catchments the differences are moderate.

\section{Discussion}

The model calibration and sensitivity analysis using the stream network with the Kappa statistics show some differences among the catchments. This could be related to differences in the geomorphologic features. The catchments with higher Kappa values (Zastlerbach, Eyach) have distinctive topographies with clearly defined valleys and concave areas. Due to a strong relationship between slope and lateral subsurface flow in the model, these topographies promote the concentration of water in the corresponding cells resulting in spatially confined stream networks which can reach higher Kappa values. However, even for those catchments the absolute Kappa value is low, but this need not necessarily indicate that the parameter identification was unsuccessful. Stream networks are line-like structures and even if groundwater is not continuously feeding the stream, the stream continuous to flow as long as the inflow into a section is larger than the loss. However, the model only simulates area of groundwater inflow into the stream, hence, the complete network cannot be simulated with this approach. This will result in relatively 


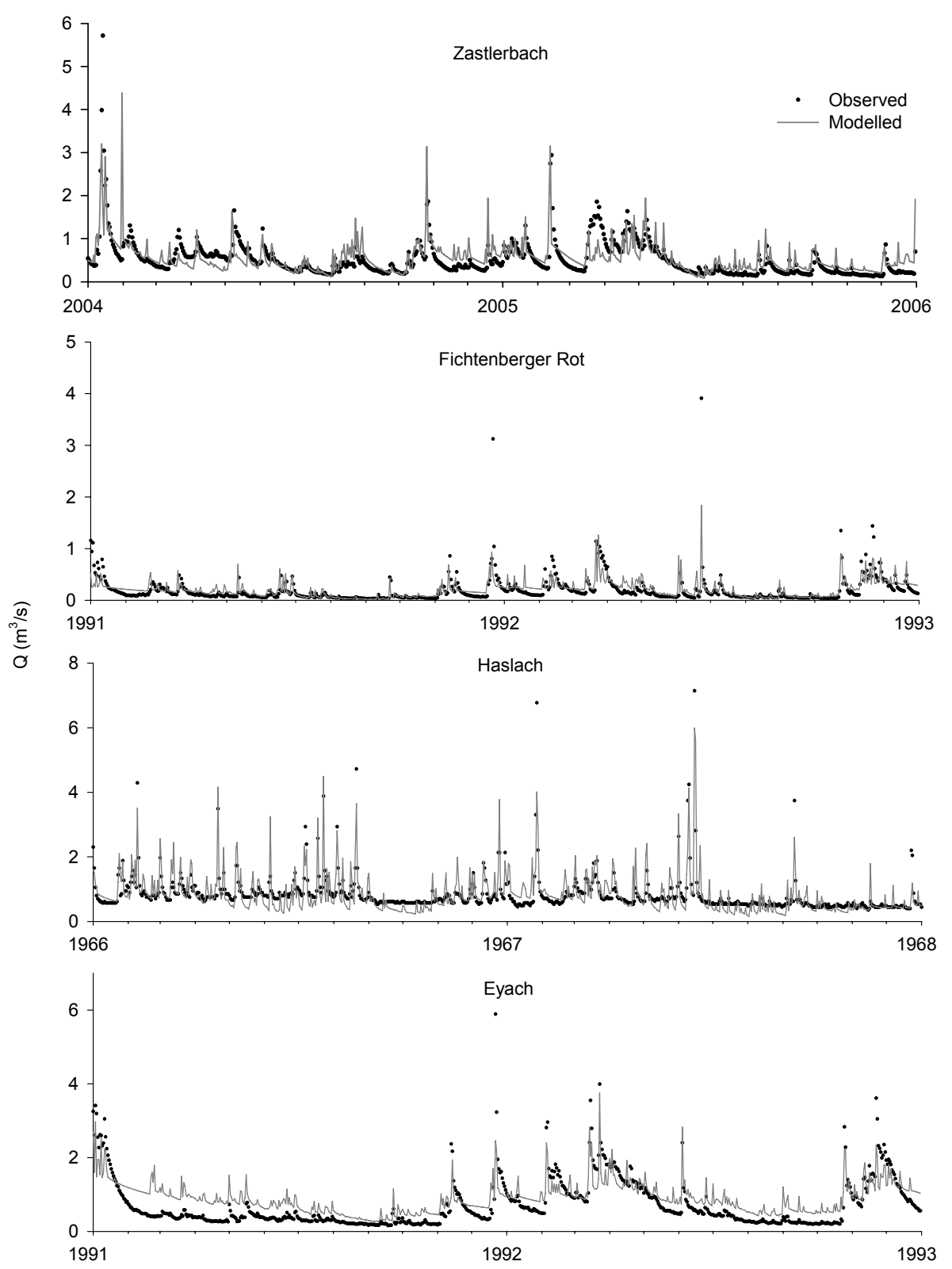

Fig. 5. Modelled and observed hydrographs of the four catchments.

low Kappa values. In addition, differences in the resolution, uncertainties of defining the exact position and conversion errors can result in deviations between the mapped and the simulated stream network (Güntner et al., 2004). Additionally, studies by Viera and Garrett (2005) and Foody (1992) have shown that rare findings, like stream cells, which account only for $4-9 \%$ for the catchment areas (using the selected grid resolution) can promote an overestimation of the chance agreement reflecting in low Kappa values. However, for the subject of parameter identification it is less important to reach absolute high Kappa values than to detect significant differences between the individual parameter sets.
Since the individual parameters are dependent on each other it is difficult to evaluate them separately. Consequently, only the transmissivity and storativity over depth are assessed. The transmissivity, which is based on the total depth, the hydraulic conductivity and the decay coefficient of the hydraulic conductivity, seems to be closely related to the dominant geologies. The transmissivity in the Zastlerbach basin, which is dominated by low conductive metaphoric rocks and shallow soils, is the lowest and consistent to previous results (Güntner et al., 2004). The optimized transmissivities of the Fichtenberger Rot, Haslach and the Eyach, where sandstones, marls and quaternary material are present, are significantly higher. Those values agree well with the 
Table 7. Water budgets with absolute and relative discharge error $(\Delta Q)$.

\begin{tabular}{lccrccrr}
\hline & $P$ & $\mathrm{AET}_{\text {mod }}$ & $\Delta S$ & $Q_{\text {obs }}$ & $Q_{\text {mod }}$ & $\Delta Q(\mathrm{~mm})$ & $\Delta Q(\%)$ \\
\hline Zastlerbach & 1426 & 404 & 38 & 912 & 984 & +72 & +7.9 \\
Fichtenberger Rot & 1008 & 577 & 45 & 350 & 386 & +36 & +10.3 \\
Haslach & 1258 & 604 & 5 & 646 & 649 & +3 & +0.4 \\
Eyach & 1475 & 521 & -10 & 769 & 963 & +194 & +25.2 \\
\hline
\end{tabular}
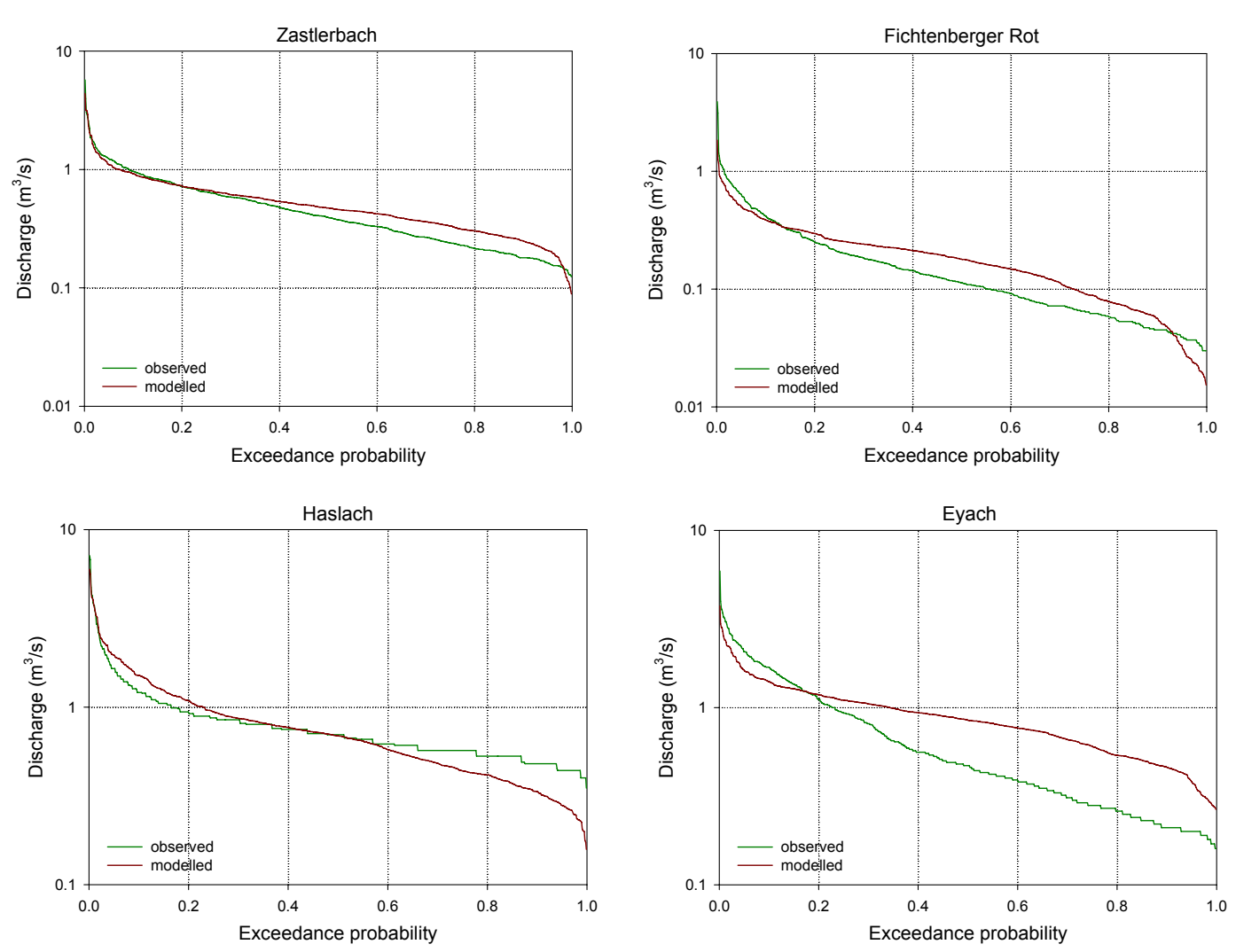

Fig. 6. Modelled and observed flow duration curves.

hydraulic conductivities which were reported in hydrogeological maps (WaBoA, 2007). Concerning the sensitivity, there is a difference between catchments with distinctive topography and flat basins. The effects of the conductivity variations become more apparent in steeper catchments because of the stronger effect of the slope on the lateral subsurface flow. It is more difficult to evaluate the results of the calculated storativities, because the sensitivity on the model performance is much lower. Similar to the results of the transmissivity, the Zastlerbach shows the lowest value, which can be linked to the metamorphic rocks and especially the shallow soils storing only little water. In the others catchments no significant differences were found which could be ascribed to similar storage properties of the soils and geology. In general, the identified parameter sets seem to be reasonable for the specific catchments.
The sensitivity analysis for the Zastlerbach catchment concerning the spatial distribution of stream cells shows also a strong dependency on transmissivity. Higher transmissivities than the optimized value (Fig. 3c and d) promote fast water flow through the slopes (without reaching saturation) converging at the valley bottom. In contrast to that, lower transmissivities (Fig. 3e and f) result in earlier saturation of the cells, leading to an overestimation of the stream extent. Compared to the reference network the best parameter fit according to Kappa statistics also shows a slight overestimation of the stream extent. Besides the relatively low transmissivity this could also be related to the resolution of the underlying DEM. A resolution of $50 \mathrm{~m}$ may not be adequate to represent the converging in the small catchments accurately. Consistent with the dotty plots, also the spatial analysis shows weak dependency on the storativity. Using climate 

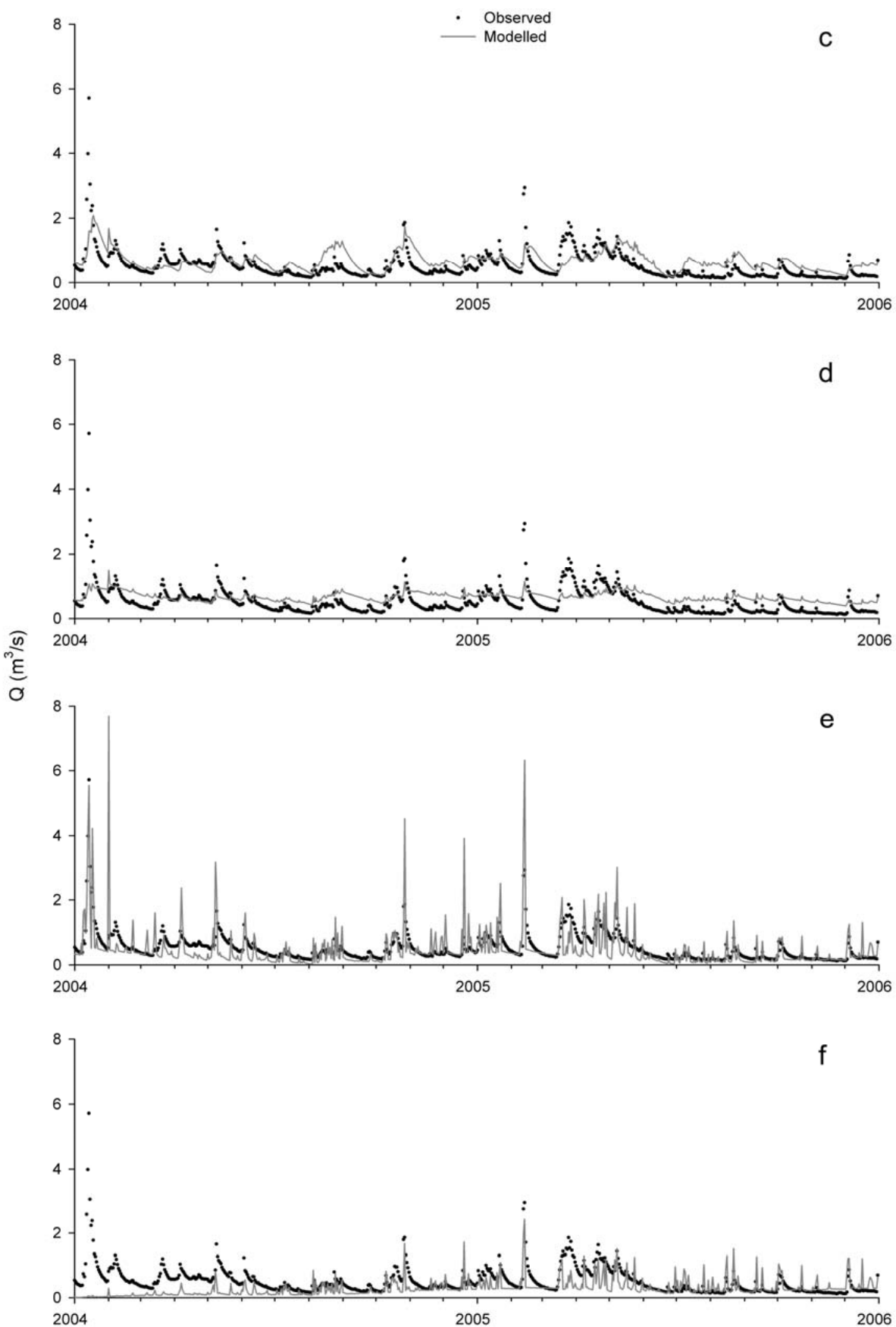

Fig. 7. Modelled and observed Zastlerbach hydrographs of the four test parameter sets specified in Table 5.

normals as model input and a one year warm-up period, we simulate kind of stationary conditions. Thus changes in storage and consequently the influences on the stream extent are small. This could lead to an underestimation of the importance of the storage parameters and have to be kept in mind when transferring the identified parameter to non-stationary rainfall-runoff applications.
Analysing the runoff predictions two major problems can generally be identified. First, the model is not able to predict the high peaks reliably, especially during spring time. One explanation may be that processes dominating the runoff generation were not implemented in the model. The model approach is based on the assumption that the runoff is dominated by subsurface runoff which agrees with the findings of Sklash and Farvolden (1979) and by saturation overland flow. 
Table 8. Comparison of model performances in other studies modelling ungauged basins.

\begin{tabular}{lc}
\hline Studies & $n_{\text {eff }}$ \\
\hline this study & $0.39-0.60$ \\
Hundecha et al., 2007 & $0.87-0.96$ \\
Parajka et al., 2005 & $0.54-0.64$ \\
Bardossy, 2007 & $0.14-0.90$ \\
\hline
\end{tabular}

However, there are additional processes that affect runoff generation in humid watersheds, not implemented in the chosen parsimonious model. For example, Uhlenbrook (1999) observed frequently precipitation on frozen soil in winter resulting in winter floods in the Zastlerbach catchment. Furthermore, infiltration excess overland flow on steep slopes, bedrock, and sealed areas can occur. Another explanation is related to the apriori defined parameters for the snowmelt model component. The second problem is the overestimation of discharge during the recession periods. The predicted response time of subsurface flow is mainly controlled by the hydraulic conductivity, the specific yield and the corresponding decay coefficients with soil depth. The problem seems to be related to the latter. If a smaller decay coefficient would have been selected during the optimization process, a faster decline could be realised. However, the storage capacity would simultaneously be diminished. Thus, the model could not assure a good simulation of the base flow periods any longer. This is definitely a limitation of the chosen parsimonious model structure and could be corrected by implementing a separate decay coefficient for hydraulic conductivity and specific yield. Also the mentioned difficulties related to the rather non-sensitive behaviour of storage parameters may play a role. Additionally, the low logarithmic efficiency in the Haslach catchment is related to the existence of a small lake in the catchment, which acts as a buffer keeping the discharge on a constant level.

The evaluation of parameter sensitivity for predicting discharge showed that the best parameter set has performed clearly better than the test parameters. The behaviour of the hydrographs can be associated with the parameter values. Parameter sets with high transmissivity ( $c$ and $d$ ) generate a delayed response. The water flows to the underground so that hardly any fast runoff components can be generated. High storativity amplifies these effects as even more water can be stored in the underground. Contrary to that, the parameter sets with low transmissivity ( $e$ and $f$ ) generate a very fast response to precipitation events and underestimate baseflow. In case of parameter set $f$ the warm-up period was not long enough to introduce steady-state conditions. The storativity is so high that almost another two years are needed until balanced conditions are reached.
The performance of the discharge predictions of the presented approach can be compared with results of previous modelling studies in ungauged basins (Table 8). Hundecha et al. (2007) established a regionalisation method transferring individual parameter values, which are linked to catchment properties, from similar gauged basins. A semi-distributed model based on the concept of the HBV (Bergström, 1995) was used for the simulations. The same model type was used by Bárdossy (2007) but instead of transferring individual parameters whole parameter sets were assigned. Parajka et al. (2005) tested different regionalisation methods using the HBV model in 320 Austrian catchments. The performances of the presented approach are not as good as the reported results especially for the maximum objective functions. However, it must be realized that the approaches have different input requirements. For example, the regionalisation by Hundecha et al. (2007) requires specific information about the ungauged basin (e.g. soils and land-use) which is not necessary for the actual approach. Additionally, in this study a relative simple and parsimonious model structure with only four parameters was applied which is not comparable to the conceptual HBV model with more parameters.

The evaluation of the water budgets and the flow duration curves shows slightly different results than those of the hydrographs. Although the highest model efficiency is reached in the Eyach catchment the highest differences in mean runoff was also observed. Most likely this effect is related to the influence of the insufficient simulation of the evapotranspiration. The simple approach applied in the presented model does not account for differences in land use and vegetation. Consequently, evapotranspiration in the completely forested Eyach catchment is underestimated and thus the discharge overestimated. In the other catchments the portion of the forest is smaller (Haslach, Fichtenberger Rot) or the mean elevation and annual precipitation is higher reducing the dominance of evapotranspiration in the water balance (Zastlerbach). The quality of the hydrographs is primarily evaluated in consideration of an adequate reflection of the runoff dynamics. The timing of the rise and fall of the peak flows is mainly controlled by parameters describing the subsurface. The absolute amount of the evapotranspiration is less important. Thus, a good realisation of the hydrographs dynamic need not necessarily implicate good simulations of the water balance.

\section{Conclusions}

The presented approach for guiding hydrological modelling in ungauged basins has shown some promising results but also some limitations. The underlying assumption that the development and initiation of stream networks is controlled by the properties of the subsurface could be plausibly confirmed by the strong dependency on transmissivity. Generally, those agree with values reported for the local 
hydrogeologies. Nonetheless no strong relationship between stream initiation and storativity could be found, making it difficult to transfer those parameters to a continuous rainfallrunoff prediction. Although the absolute values were relatively low, the Kappa statistics seems to be suitable to evaluate explicit simulation of stream networks since significant relative differences between good and poor simulations were found. However, a connection between the performances' quality and geomorphologic features of the catchments could be seen. Additionally, we suggest using high resolution DEMs allowing a better definition of groundwater inflow in the streams.

The modifications and simplification of the hillslope model Hill-Vi was problematic. Since the unsaturated zone was removed to assure fast and robust model runs, the evapotranspiration was represented by a simple correlation based on the groundwater table depth. However, the results of the water balances and the hydrographs evaluations showed that this representation does not always deliver satisfactory simulations. The same applies to the combination of the decay coefficients of the specific yield and the saturated hydraulic conductivity in just one parameter. This caused a significant reduction in the model performance due to a poor representation of the discharge recession and could be corrected by the implementation of two independent coefficients. Despite those limitations, the model performed quite well with results close to the performance of regionalisation methods, which were carried out with more detailed models. It seems that the differences are caused by the already mentioned problems, which could be removed by applying a more sophisticated model structure.

In general, the process-based modelling of stream networks seems to be a good alternative to gain information about the parameters describing subsurface processes. As mentioned in the introduction the study should not present a stand-alone calibration procedure. Thus we suggest combining this approach with regionalisation methods to constrain the possibilities of suitable parameter sets in ungauged basins or even to use this approach in gauged basins to constrain parameters describing subsurface processes. A major advantage is the low data requirement. Besides the climatic forcing data, only a digital elevation model and a stream network map are necessary. Furthermore, additional information on the subsurface can be gained by the interpretation of the physically based parameters. Aside the ungauged basin problem and combined with discharge data, explicit modelling of stream network could be used to improve parameterization as well as conceptualization.

Edited by: A. Bronstert

\section{References}

Abdulla, F. A. and Lettenmaier, D. P.: Development of regional parameter estimation equations for a macroscale hydrologic model, J. Hydrol., 197, 230-257, 1997.

Bárdossy, A.: Calibration of hydrological model parameters for ungauged catchments, Hydrol. Earth Syst. Sci., 11, 703-710, doi:10.5194/hess-11-703-2007, 2007.

Bauer, P., Gumbricht, T., and Kinzelbach, W.: A regional coupled surface water/groundwater model of the Okavango Delta, Botswana, Water Resour. Res., 42, W04403, doi:10.1029/2005wr004234, 2006.

Bergström, S.: The HBV model, in: Computer Models of Watershed Hydrology, edited by: Singh, V.P., Water Resources Publications, Littleton, Colorado, USA, 1995.

Beven, K.: Prophecy, reality and uncertainty in distributed hydrological modelling, Adv. Water Resour., 16, 41-51, 1993.

Blöschl, G.: Rainfall-runoff modelling of ungauged catchments, article 133, in: Encyclopaedia of Hydrological Sciences, edited by: Anderson, M. G., J. Wiley \& Sons, Chichester, 2061-2080, 2005.

Blöschl, G., Kirnbauer, R., Jansa, J., Kraus, K., Kuschnig, G., Gutknecht, D., and Reszler, C.: Einsatz von Fernerkundungsmethoden zur Eichung und Verifikation eines flächendetaillierten Schneemodells (Using remote sensing methods for calibrating and verifying a spatially distributed snow model), Österreichische Wasser- und Abfallwirtschaft, 54, 1-16, 2002.

Cohen, J.: A coefficient of agreement for nominal scales, Educ. Psychol. Meas., 20, 37-46, doi:10.1177/001316446002000104, 1960.

Congalton, R. G. and Green, K.: Assessing the accuracy of remotely sensed data: principles and practices, Lewis Publishers, Boca Raton, 137 pp., 1999.

de Vries, J. J.: Dynamics of the interface between streams and groundwater systems in lowland areas, with reference to stream net evolution, J. Hydrol., 155, 39-56, 1994.

de Vries, J. J.: Seasonal expansion and contraction of stream networks in shallow groundwater systems, J. Hydrol., 170, 15-26, 1995.

Dunne, T.: Runoff production in a humid area, Ph.D. Thesis, Johns Hopkins University, Baltimore, 108 pp., 1969.

Foody, G. M.: On the compensation for chance agreement in image classification accuracy assessment, Photogramm. Eng. Rem. S., 58, 1459-1460, 1992.

Freeze, R. A. and Cherry, J. A.: Groundwater, Prentice-Hall, Englewood Cliffs, NJ, 604 pp., 1979.

Grayson, R. B. and Blöschl, G.: Spatial patterns in catchment hydrology: Observations and Modelling, Cambridge University Press, Cambridge, UK, 404 pp., 2000.

Grayson, R. B., Blöschl, G., Western, A. W., and McMahon, T. A.: Advances in the use of observed spatial patterns of catchment hydrological response, Adv. Water Resour., 25, 1313-1334, 2002.

Güntner, A., Seibert, J., and Uhlenbrook, S.: Modeling spatial patterns of saturated areas: An evaluation of different terrain indices, Water Resour. Res., 40, W05114, doi:10.1029/2003wr002864, 2004.

Hewlett, J. D. and Hibbert, A. R.: Factors affecting the response of small watersheds to precipitation in humid areas, in: Forest Hydrology, edited by: Sopper, W. and Lull, H. W., Pergamon, 
Oxford, 275-290, 1967.

Horton, R. E.: Erosional development of streams and their drainage basins; hydrophysical approach to quantitative morphology, Geol. Soc. Am. Bull., 56, 275-370, 1945.

Hundecha, Y., Zehe, E., and Bárdossy, A.: Regional parameter estimation from catchment properties for the prediction of ungauged catchments, in: Proceedings of the PUB Kick-off meeting held in Brasilia, 20-22 November, edited by: Hubert, P., Schertzer, D., Takeuchi, K., and Koide, S., IAHS Publications, 309, 22-29, 2007.

Jost, G., Dan Moore, R., Weiler, M., Gluns, D. R., and Alila, Y.: Use of distributed snow measurements to test and improve a snowmelt model for predicting the effect of forest clear-cutting, J. Hydrol, 376, 94-106, 2009.

Kokkonen, T. S., Jakeman, A. J., Young, P. C., and Koivusalo, H. J.: Predicting daily flows in ungauged catchments: model regionalization from catchment descriptors at the Coweeta Hydrologic Laboratory, North Carolina, Hydrol. Process., 17, 2219-2238, 2003.

Lobkovsky, A. E., Smith, B. E., Kudrolli, A., Mohrig, D. C., and Rothman, D. H.: Erosive dynamics of channels incised by subsurface water flow, J. Geophys. Res., 112, F03S12, doi:10.1029/2006jf000517, 2007.

Merz, R. and Blöschl, G.: Regionalisation of catchment model parameters, J. Hydrol., 287, 95-123, 2004.

Monserud, R. A. and Leemans, R.: Comparing global vegetation maps with the Kappa statistic, Ecol. Model., 62, 275-293, 1992.

Nash, J. E. and Sutcliffe, J. V.: River flow forecasting through conceptual models part I - A discussion of principles, J. Hydrol., 10, 282-290, 1970.

Nathan, R. J. and McMahon, T. A.: Identification of homogeneous regions for the purposes of regionalisation, J. Hydrol., 121, 217238, 1990.

Parajka, J., Merz, R., and Blöschl, G.: A comparison of regionalisation methods for catchment model parameters, Hydrol. Earth Syst. Sci., 9, 157-171, doi:10.5194/hess-9-157-2005, 2005.

Refsgaard, J. C.: Towards a formal approach to calibration and validation of models using spatial data, in: Spatial Patterns in Catchment Hydrology: Observations and Modelling, edited by: Grayson, R. and Blöschl, G., Cambridge University Press, New York, 329-354, 2001.

Rodriguez-Iturbe, I. and Rinaldo, A.: Fractal River Networks: Chance and Self-Organization, Cambridge University Press, New York, 547 pp., 1997.
Rodríguez-Iturbe, I. and Valdés, J. B.: The geomorphologic structure of hydrologic response, Water Resour. Res., 15, 1409-1420, doi:10.1029/WR015i006p01409, 1979.

Seibert, J.: Regionalisation of parameters for a conceptual rainfallrunoff model, Agr. Forest Meteorol., 98-99, 279-293, 1999.

Selker, J. S., Duan, J., and Parlange, J.-Y.: Green and Ampt Infiltration into Soils of Variable Pore Size with Depth, Water Resour. Res., 35, 1685-1688, 1999.

Sivapalan, M., Takeuchi, K., Franks, S. W., Gupta, V. K., Karambiri, H., Lakshmi, V., Liang, X., McDonnell, J. J., Mendiondo, E. M., O’Connel, P. E., Oki, T., Pomeroy, J. W., Schertzer, D., Uhlenbrook, S., and Zehe, E.: IAHS decade on Predictions of Ungauged Basins (PUB), 2003-2012: Shaping an exciting future for the hydrological sciences, Hydrolog. Sci. J., 48, 857-879, 2003

Sklash, M. G. and Farvolden, R. N.: The role of groundwater in storm runoff, J. Hydrol., 43, 45-65, 1979.

Thornthwaite, C. W.: An Approach toward a rational classification of climate, Geogr. Rev., 38, 55-94, 1948.

Troch, P. A., De Troch, F., Mancini, M. P., and Wood, E. F.: Stream network morphology and storm response in humid catchments, Hydrol. Process., 9, 575-587, 1995.

Uhlenbrook, S.: Untersuchung und Modellierung der Abflussbildung in einem mesoskaligen Einzugsgebiet, Freiburger Schriften zur Hydrologie, 10, Institut für Hydrologie, Universität Freiburg, 201 pp., 1999.

Viera, A. J. and Garrett, J. M.: Understanding interobserver agreement: The Kappa statistic, Fam. Med., 37, 360-363, 2005

WaBoA: Wasser- und Bodenatlas Baden-Württemberg, 3. Lieferung, Umweltministerium Baden-Württemberg, Landesanstalt für Umwelt, Messungen und Naturschutz Baden-Württemberg, 2007.

Weiler, M. and McDonnell, J.: Virtual experiments: a new approach for improving process conceptualization in hillslope hydrology, J. Hydrol., 285, 3-18, 2004.

Weiler, M. and McDonnell, J.: Testing nutrient flushing hypotheses at the hillslope scale: A virtual experiment approach, J. Hydrol., 319, 339-356, 2005.

Wigmosta, M. S. and Lettenmaier, D. P.: A comparison of simplified methods for routing topographically driven subsurface flow, Water Resour. Res., 35, 255-264, doi:10.1029/1998wr900017, 1999. 